\title{
Craniodiaphyseal dysplasia
}

INSERM

\section{Source}

INSERM. (1999). Orphanet: an online rare disease and orphan drug data base.

Craniodiaphyseal dysplasia. ORPHA:1513

Craniodiaphyseal dysplasia is a rare sclerotic bone disorder with a variable phenotypic expression with massive generalized hyperostosis and sclerosis, particularly of the skull and facial bones, that may lead to severe deformity. 